\title{
Ideologias de Desenvolvimento em jornais de Santarém-PA nas décadas de 1960 e 1970
}

\author{
André das Chagas Santos ${ }^{1}$, Deyse Cristina Coelho da Silva ${ }^{2}$ e \\ Elen Carina Duarte Ferreira ${ }^{3}$
}

\begin{abstract}
1 Doutorando em Sociedade, Natureza e Desenvolvimento na Universidade Federal do Oeste do Pará, Meste em Educação, Graduado em História. Professor do Curso de Ciências Econômicas na Universidade Federal do Oeste do Pará, Brasil. Email: andrecriz2010@hotmail.com

2 Discente do 6o período do curso de Ciências Econômicas na Universidade Federal do Oeste do Pará, Brasil. Email: deyse_criszinha17@hotmail.com

3 Discente do 6ำ período do curso de Ciências Econômicas na Universidade Federal do Oeste do Pará, Brasil. Email: elencarinaduarte@gmail.com
\end{abstract}

RESUM 0: 0 artigo discute a importância dos aspectos políticos, históricos e sociais nas décadas de 1960 e 1970, com o objetivo de compreender o contexto da implantação dos projetos de Desenvolvimento que afetaram o município de Santarém (Oeste do Pará), além de analisar as perspectivas de diferentes vertentes a respeito do desenvolvimento no século XX. Essa compreensão é fundamental para refletir a perspectiva da população amazônica na elaboração ou recepção destas políticas, visto que essas foram elaboradas a partir dos centros políticos brasileiros que consideravam a região amazônica como área periférica. Em termos práticos, a pesquisa foi realizada nas seguintes etapas: (a) revisão bibliográfica sobre o histórico-social do período estudado, o conceito de desenvolvimento e problemática de desenvolvimento no século XX e; (b) levantamento e análise de fontes primárias. (c) pesquisa em jornais na cidade de Santarém para compreender como a imprensa - parte da população, portanto - se posicionou em relação a estas políticas estatais. Como resultados, observou-se que os projetos para viabilizar a integração mantiveram seu foco na exploração e extração de recursos naturais da Região Amazônica. Economicamente a Amazônia era valorizada por ser uma vasta região cheia de riquezas que, de acordo com o pensamento da época, poderiam ser utilizadas para ajudar economicamente o país.

Palavras-chave: Desenvolvimento, Amazônia, Santarém - Pará

\section{Ideologies of Development in newspapers of Santarém-PA in the decades of 1960 and 1970}

ABSTRACT: The article discusses the importance of the political, historical and social aspects in the decades of 1960 and 1970, in order to understand the context of the implementation of development projects that affected the city of Santarém (West of Pará), in addition to analyzing the prospects of different aspects concerning the development in the 20th century. This understanding is fundamental to reflect the perspective of the Amazon population in the preparation or receipt of such policies, since these were prepared from Brazilian political centres who regarded the Amazon region as peripheral area. In practical terms, the survey was conducted in the following steps: (a) literature review on the social history of the period studied, the concept of development and problems of development in the 20th century; (b) survey and analysis of primary sources. (c) research papers in the city of Santarém to understand how the press - part of the population, therefore-if positioned on these State policies. As a result of the article, it was observed that the projects to achieve this integration have kept their focus on exploration 
and extraction of natural resources in the Amazon region. Economically the Amazon was valued for being a region filled with riches, according to the thinking of the time, could be used to help the country economically.

Keywords: Development, Amazon, Santarém - Pará

\section{INTRODUÇÃO}

Muito se questiona sobre a forma de integração da Amazônia ao Brasil, e seu processo de desenvolvimento. Becker (2009, p.135) ressalta que "um componente comum perpassa todos os interesses: o desejo de se desenvolver", com a Amazônia não aconteceu de forma diferente, para tanto, é preciso compreender o conceito de desenvolvimento.

Desenvolvimento é o "processo dinâmico de melhoria, que implica mudanças, evolução e crescimento produzindo impactos estruturantes no nível da produção, da renda e do consumo da população, elevando a qualidade de vida da região" (SANTOS; SANTOS, 2012 p.7). Para os autores é fundamental, um modelo de gestão acessível para que haja desenvolvimento, no qual as metas e os objetivos estejam de acordo com a realidade do local.

O município de Santarém, na Região do Oeste do Pará, vivenciou nas décadas de 1960 e 1970, um processo de desenvolvimento em que os principais objetivos eram de integração e ocupação territorial, assim como em toda a Região Amazônica. De acordo com Becker (2009), as políticas públicas para a região não possibilitaram um desenvolvimento regional efetivo, isso em razão da forma com que foram articulados os planos de integração.

O objetivo deste trabalho é refletir sobre concepções de desenvolvimento presentes nos jornais da cidade de Santarém nas décadas de 1960 e 1970. Entre eles serão abordados a Rodovia Transamazônica, Rodovia Br-163 e Hidroelétrica de Curuá-una. Propõe-se, também, a realizar uma análise nos jornais locais do respectivo período, a partir da perspectiva da população santarena quanto à implantação desses projetos de integração da Amazônia. Ademais, compreender as diferentes vertentes do Desenvolvimento no século XX.

A pesquisa foi realizada a partir de uma revisão bibliográfica, feita através dos levantamentos de referências sobre os conceitos de Desenvolvimento de diferentes teóricos. Concomitantemente, foram realizadas pesquisas documentais no Instituto Boanerges Sena (um arquivo particular que guarda importantes documentos sobre a história da Cidade de Santarém e região), inclusive exemplares de jornais das décadas 1960 e 1970, a respeito do posicionamento da população santarena sobre a implantação desses projetos de integração nacional.

As grandes questões que nortearam a pesquisa foram: como as obras de integração nacional foram recebidas no Oeste do Pará? Como a população local assimilou a ideologia do desenvolvimento naquele momento histórico? Como está o cenário atual desses projetos? Um trabalho desta natureza torna-se importante, pois não são 
facilmente encontradas pesquisas que abordem essa temática a partir da perspectiva local. Desta forma, para compreender a realidade atual, é necessário recorrer ao pensamento do processo de desenvolvimento da época, da qual decorreram inúmeras transformações sociais e políticas que se presenciam hoje.

\section{CONCEPÇÕES DE DESENVOLVIMENTO NO DECORRER DO SÉCULO XX}

A lógica da produção capitalista atingiu condições globais a partir de meados do século XX. Neste momento, a noção de desenvolvimento esteve associada "a ideia de possibilidade de progresso e crescimento ilimitado, e se constituiu como um dos pilares da sociedade industrial ocidental" (SCOTTO; CARVALHO; GUIMARÃES, 2011, p. 15). Nesse contexto histórico, Santos e Santos (2012), consideram que o governo britânico associava o desenvolvimento à responsabilidade de cuidar do bem-estar (...) e, o governo americano utilizou o termo para marcar o início de uma nova era no mundo, onde dizia: "O que imaginamos é um programa de desenvolvimento baseado nos conceitos de uma distribuição justa e democrática". (BREDA e ANDRADE, 2002, p.03)

A Comissão Econômica para a América Latina e o Caribe (CEPAL), segundo Bochi e Gargiulo (2000) atingiu o seu auge nas duas décadas seguintes 1960 e 1970 (...) com a *** missão de pesquisar e de realizar estudos econômicos, os quais fossem possíveis comprovar as políticas de desenvolvimento na América Latina.

Nos países subdesenvolvidos, era necessário programar uma nova rota para seu desenvolvimento, que em síntese, era encontrada nas teses sobre a substituição de importações que são adotadas durante o período de auge do desenvolvimentismo, entre as décadas de 1950 e 1960. (...) nos anos 50, a industrialização por subsitituição de importações; nos anos 60, a agenda de reformas e as teorias econômicas e sociológicas da estagnação, da dependência e da heterogenidade estrutural; nos anos 70, os "estilos"de crescimento e a reorientação da industrialização para promover exportações industriais ; e nos anos 80, renegociação da industrialização da dívida, controle da inflação e ajuste expansivo. (BOCHI E GORGIULO, 2000, p. 2,4,5).

É importante frisar, nesse contexto, as grandes transformações que ocorrera nos países subdesenvolvidos ressaltadas e estudadas pela CEPAL nas décadas de 1960 e 1970. Essas mudanças desencadeavam o mesmo pensamento, o desejo de se desenvolver. Contudo, é fundamental diferenciar os termos Desenvolvimento e Crescimento.

0 desenvolvimento tem um lugar mediante aumento de produtividade no nível do conjunto econômico complexo. Esse aumento de produtividade (e da renda per capita) é determinado por fenômenos de crescimento que têm lugar em subconjunto ou setores particulares. As modificações de estrutura são transformações nas relações e proporções internas do sistema econômico, as quais têm como causa básica modificações nas formas de 
produção, mas que não poderiam concretizar sem modificações na forma de distribuição e utilização de renda. (SANTOS e SANTOS, 2012, p.6).

Compreende-se, então, segundo os autores, que o crescimento econômico referese diretamente na renda da população, considerando o indice do Produto Interno Bruto (PIB) e que o desenvolvimento está realicionado a elevação e a qualificação da vida da população ao analisar o Índice de Desenvolvimento Humano (IDH) do local.

Lima e Simões (2009) observam que o teórico Hirschiman defende o progresso do desenvolvimento econômico o qual não ocorre em toda parte, concentra-se onde se inicia, por isso é importante que ocorra uma análise estratégica e um planejamento desse desenvolvimento. Essa teoria do Desenvolvimento elaborada por Hirschman tem como objetivo principal "uma série de projetos que produzam efeitos favoráveis sobre o fluxo de renda e em uma variedade de áreas (administração pública, educação, saúde, transportes, urbanização, agricultura, indústria, etc) cuja realização é limitada pela capacidade de investimento local. (...) projetos de acordo com o retorno social". (LIM A e SIM ÕES, 2009, p. 19).

Em uma perspectiva especifíca, torna-se indispensável compreender o Desenvolvimento local. Esse, por sua vez, promove o dinamismo econômico e a melhoria da qualidadede vida da populção, ao considerar as transformações nas bases econômicas a nível local e explorar as capacidades e as potencialidades do mesmo (BUARQUE, 1999, p. 1) define que esse "desenvolvimento deve elevar as oportunidades sociais e a viabilidade e competitividade da economia local, aumentando a renda e as formas de riqueza , ao mesmo tempo em que assegura a conservação dos recursos naturais".

Esses modelos de desenvolvimento sofreram várias críticas, pois o desenvolvimento movido por tecnologias vinha acompanhado de concentração de renda, e nos países em desenvolvimento não foi capaz de reduzir os níveis de pobreza. Celso Furtado (1974) ao analisar o caso do desenvolvimento brasileiro, observou que a ideia de desenvolvimento se dava de forma mitológica, ou seja, uma ideologia que não seria capaz de generalizar o padrão de vida dos países ricos, e que ao contrário, o modelo de desenvolvimento acirrava ainda mais as desigualdades sociais.

Além da constatação da falência social deste modelo desenvolvimentista, percebeu-se, ainda, que a expansão da ideologia do desenvolvimento capitalista, na forma como explorava os recursos naturais, representava sérios riscos a vida na terra. Diante deste contexto surgiram diversos pensadores nas ciências humanas e sociais que passaram a discutir a crise ambiental. Uma das primeiras autoras discutir 0 assunto foi Rachel Carson, em 1962, com o Livro "A primavera silenciosa". Nesta obra a autora denuncia os efeitos do pesticida DDT na natureza e para os seres humanos.

A ideia de Crise Ambiental surgiu a partir da constatação que as mudanças no campo ambiental não foram causadas apenas pela dinâmica e processo naturais. Deste momento em diante as discussões sobre as transformações naturais passaram a incluir o elemento humano, e consequentemente, o estudo sobre estas questões passaram a ser objeto de estudo das ciências humanas e sociais, assim, 0 ideal de 
sustentabilidade surge como uma estratégia de utilizar os recursos naturais de maneira consciente.

Como mostra Nascimento (2010) a respeito da sustentabilidade:

A ideia de sustentabilidade ganha corpo e expressão política na adjetivação do termo desenvolvimento, fruto da percepção de uma crise ambiental global. Essa percepção percorreu um longo caminho até a estruturação atual, cujas origens mais recentes estão plantadas na década de 1950, quando pela primeira vez a humanidade percebe a existência de um risco ambiental global: a poluição nuclear. Os seus indícios alertaram os seres humanos de que estamos em uma nave comum, e que problemas ambientais não estão restritos a territórios limitados. (NASCIM ENTO, 2012, p. 52).

Ccompreendeu-se, desta maneira, que a forma como os homens produziam as suas condições materiais de existência dentro do modo de produção capitalista provocavam sérios danos ao meio ambiente, e estas relações precisavam de sérias mudanças.

Habermas (1968) atribuiu as responsabilidades dos problemas ambientais ao modo de produção capitalista e busca infinita pela produção da mais-valia, e que 0 crescimento da produção e o aumento populacional seriam limitadas pela capacidade de recuperação do meio ambiente. Portanto seria importante uma revisão no modelo de produção.

\section{POĹTICAS DE INTEGRAÇÃO NACIONAL E O CONTEXTO AMAZÔNICO}

Amazônia é a maior região brasileira, com cerca de 4,8 milhões de $\mathrm{km}^{2}$, ocupa mais da metade do território nacional. Durante um longo período foi esquecida, tanto por portugueses (no período de colonização), e posteriormente pelas autoridades brasileiras (no período do império) e parte da República. Sua economia esteve sempre ligada ao extrativismo vegetal, exportando para a Europa produtos como o cacau, castanha-do-pará.

A atividade extrativista amazônica alcançou grande repercussão no mercado nacional e internacional no final do século XIX, com a exploração da borracha, extraída da seringueira (Hevea brasiliensis). Esse período trouxe riqueza para a região, porém não resolveu os problemas de desigualdade social e de baixa densidade demográfica que a caracterizam. Após a fase de bons preços da borracha no mercado internacional, a região amazônica foi mais uma vez esquecida pelo governo federal.

Para garantir tal integração e expansão do mercado interno, eram fundamentais algumas correções em relação "à vulnerabilidade a defesa, segurança e soberania nacionais e incrementar sua densidade populacional, estabelecer vias de comunicações e consolidar a ocupação do território através de uma rede de núcleos urbanos e vias de circulação caracterizam-se por essas correções". (ARM ENTANO, 2010, p. 3). Dessa forma, é importante refletir sobre as estrategias de desenvolvimento para cada 
região, ao considerar as especificidades locais.

Neste contexto, a partir de meados do século XX, as autoridades brasileiras voltaram o olhar para o norte. A atividade de mineração foi uma das que mais se beneficiaram. Nesta época foram encontradas jazidas de ouro, ferro, manganês, além da possibilidade de se encontrar bauxita, cobre, e até petróleo e gás natural. Foram instalados projetos de extração mineral como o projeto Grande Carajás, onde são extraídos vários tipos de minérios, sobretudo o ferro. Uma região que ficou bastante conhecida foi Serra Pelada, onde é extraído ouro desde o fim da década de 1970. No estado do Amapá se desenvolve a extração do manganês, sendo que quase a totalidade das exportações é destinada aos Estados Unidos da América.

O Estado também buscou promover o assentamento de produtores agrícolas as margens de rodovias, construídas neste período, como a Transamazônica, a Perimetral Norte, a Cuiabá - Rio Branco e a Cuiabá-Santarém, que também permitiriam o transporte de cargas e passageiros. Nota-se que esses projetos de desenvolvimento, conforme Armentano (2010), previam a construção de rodovias, e instalação de projetos agropecuários e de mineração na Amazônia. A intenção do governo era povoar as terras da região e fazer a Integração Nacional. Para a viabilização do projeto, 0 governou criou órgãos como a Superintendência de Desenvolvimento da Amazônia (SUDAM ), e a Superintendência da Zona Franca de M anaus (SUFRAM A) Outra medida adotada foi a instalação de grandes empresas na região. Também foram concedidos incentivos fiscais às empresas que se instalassem. "Dentre os principais projetos, implantados na Amazônia neste momento estão o PIN - Programa de Integração Nacional e o PROTERRA - Programa de Redistribuição de Terras e Estímulo à Agroindústria no Norte e Nordeste". (ARM ENTANO, 2010, p. 4)

0 governo militar também incentivou a migração de pequenos trabalhadores do sul do país para a região Amazônica. Foi marcante a influência de uma campanha de propaganda com o seguinte lema: Terra sem homens para homens sem terra. Além do slogan, havia promessa de terras, financiamentos, estrutura como água, energia elétrica, serviço de saúde, educação, estradas para o escoamento da produção. Estes imigrantes chegaram à região para formarem as agrovilas. Este modelo de povoação em sua maioria não prosperou, pois a maior parte das promessas do governo não foram cumpridas. Os imigrantes que não conseguiram prosperar voltaram para 0 sul do país, ou mudaram para cidades como Belém e Manaus, engrossando as periferias e a criminalidade.

Rodovias como a Santarém-Cuiabá, Belém-Brasília, Transamazônica foram abertas nessa época. Segundo as propagandas do governo, a abertura dessas rodovias traria progresso e desenvolvimento para a região. A seguir, serão apresentadas 4 imagens das Rodovias citadas. A primeira e terceira mostram o início da Construção da rodovia Transamazônica (BR-230) na década de 70, rede rodoviária que, posteriormente, acabou abandonada, a situação em período chuvoso. A segunda e a quarta mostram também o início da construção da Br-163 a qual possibilitará transição de Santarém- 
PA a Cuiabá-MT e as dificuldades enfrentadas no período chuvoso.

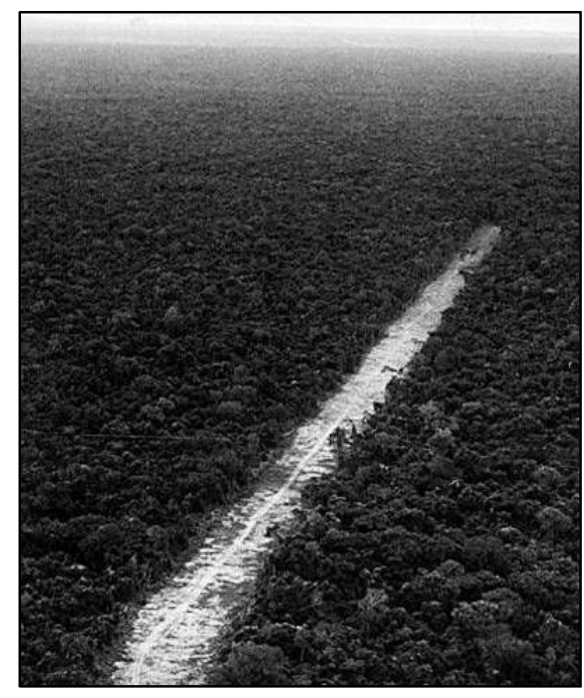

Figura 1 - Construção da Rodovia Transamazônica (BR-230).

Fonte: Fotografia folha uol

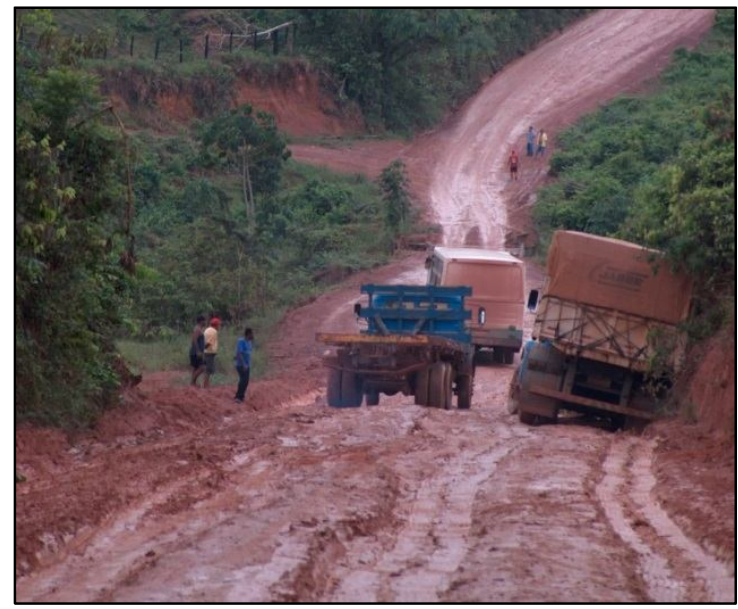

Figura 3-BR-163 na Transamazônica parte sem asfaltamento em periodo chuvoso Fonte: Folha uol

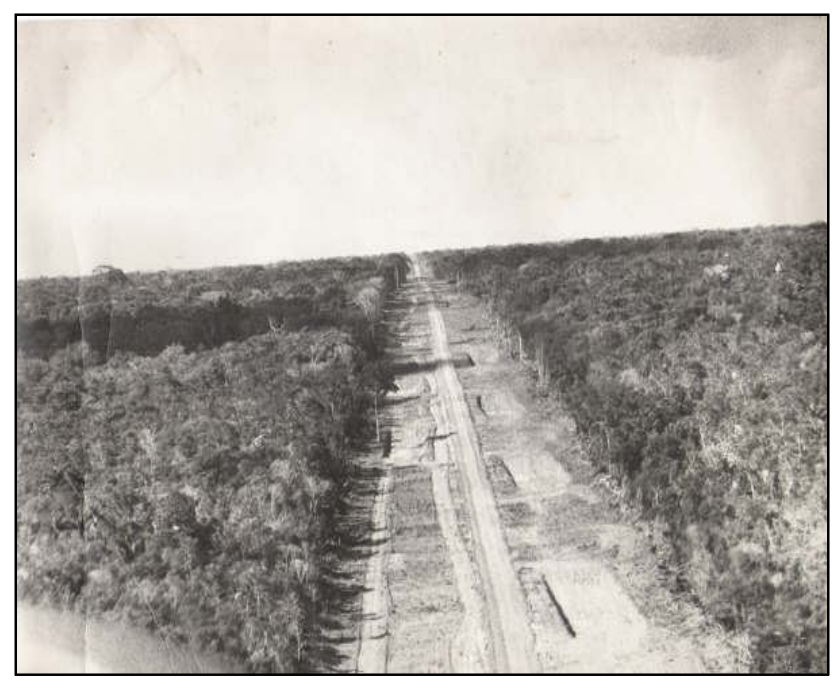

Figura 2 - Rodovia $\mathrm{Br}-163$ Fonte: Critica uol

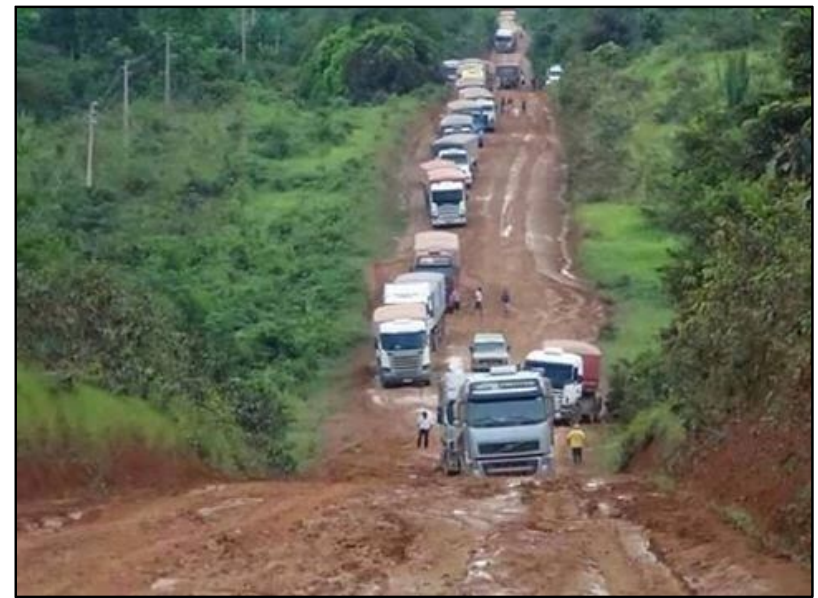

Figura 4 BR- 163 parte sem asfaltamento em periodo chuvoso Fonte:

Fonte: MT aqui onlline

Ao considerar os aspectos políticos, o Programa Estratégico de Desenvolvimento elaborado em 1968, durante o governo de Costa e Silva (1967-1969), segundo Martinoli (2004), priorizou investimentos nas áreas de produção agrícola e infraestrutura de transporte, energia e telecomunicações. Com relação à política industrial, assim como Castello Branco, Costa e Silva privilegiou o desenvolvimento industrial da empresa privada, nacional e multinacional.

Em 1967 teve início o período conhecido como 'milagre econômico', marcado por um processo de acelerado crescimento econômico e de expansão industrial, que levou ao aumento da produção industrial, o crescimento do 
nível de emprego, 0 aumento das exportações, o crescimento da renda per capita, a redução da inflação e o aumento da arrecadação. No auge do período do milagre econômico, o Plano de M etas e Bases de Ação do Governo (1970-1973), elaborado no governo de Médici e centrado na manutenção do status quo, sistematizou mais de duzentos projetos prioritários que deveriam ser realizados no período de 1970-1973 (MARTINOLI, 2004,p. 65).

Para atender a estrutura de desenvolvimento proposto pelos militares para a região a região amazônica, seria necessária a construção de usinas geradoras de energia elétrica. Neste período, foram construídas usinas hidrelétricas como é o caso da usina de Balbina no Amazonas, e de Tucuruí e Curuá-una no Pará. É importante ressaltar que o principal objetivo da construção dessas usinas foi fornecer estrutura para abrigar os grandes projetos, e não para beneficiar a população.

\section{AS IDEOLOGIAS SOBRE O DESENVOLVIM ENTO NOS JORNAIS DE SANTARÉM}

Na pesquisa realizada foram encontrados dois jornais de publicação semanal, 0 jornal de Santarém e o Jornal do Baixo Amazonas, com 15 notícias abordando diretamente a temática do desenvolvimento e políticas públicas federais para a Amazônia. Sendo que as principais obras noticiadas: a construção da Usina Hidrelétrica de Curuá-una; a abertura rodovia BR 163; a construção do porto das Docas do Pará; além do levantamento da proposta de criação da zona franca de Santarém. 0 quadro a seguir apresenta as principais notícias apresentadas nos jornais pesquisados, além da descrição do conteúdo da notícia.

QUADRO 1 Referente as notícias dos Jornais de Santarém e Baixo Amazonas

\begin{tabular}{|c|c|c|c|}
\hline Jornais & $\begin{array}{l}\text { Quantidade de notícias } \\
\text { em cada jornal }\end{array}$ & Assuntos mais abordados & $\begin{array}{l}\text { Quantidade de notícias no } \\
\text { jornal por tema }\end{array}$ \\
\hline \multirow[t]{5}{*}{ Baixo Amazonas } & \multirow[t]{5}{*}{5} & Porto & Um texto \\
\hline & & INCRA & Um texto \\
\hline & & Evolução econômica & Um texto \\
\hline & & Zona Franca em Santarém & Um texto \\
\hline & & Atividades agrícolas & Um texto \\
\hline \multirow[t]{8}{*}{ Jornal de Santarém } & \multirow[t]{8}{*}{10} & Construção da usina de Curuáuna & Um texto \\
\hline & & BR 163 & Um texto \\
\hline & & Transamazônica & Um texto \\
\hline & & M etas de desenvolvimento & Um texto \\
\hline & & Presidente M édici & Dois textos \\
\hline & & $\begin{array}{l}\text { Projetos para ocupação de terras } \\
\text { cortadas pelas estradas da Amazô- } \\
\text { nia }\end{array}$ & Um texto \\
\hline & & $\begin{array}{l}\text { Progresso nacional e regional } \\
\text { trazidos pela ditadura }\end{array}$ & Dois textos \\
\hline & & Chegada dos sulistas em Santarém & Um texto \\
\hline
\end{tabular}


A seguir analisam-se os dados das notícias dos jornais ${ }^{1}$ que apresentam as perspectivas da mídia para os cidadãos santarenos da época, os quais encaravam a chegada de grandes empreendimentos para a região como uma oportunidade de desenvolvimento, como ressalta o Jornal de Santarém de 1973:

Tudo indica que, realmente, vamos ter a concretização do grande sonho de todos os santarenos, e porque também não dizer, de todos os brasileiros que conhecem a Pérola do Tapajós e tem confiança no seu futuro. (...) a grande festa de inauguração da primeira usina hidro-elétrica da Amazônia, que vai gerar energia em abundância para acelerar o progresso de Santarém e de toda a região circunvizinha. Devemos pois aguardar com fé a realização dessa grande obra e até mesmo fazer preces a Deus, para que continue iluminando e protegendo todos aqueles que estão ligadas à grande realização, a fim de que tudo possa correr conforme está previsto e nós possamos, dentro em breve, viver as grandes alegrias de ver concretizado esse grande sonho. (JORNAL DE SANTARÉM, 1973, s/p).

Através destes relatos é possível perceber o quanto a midia santarena induzia os cidadãos a associar os grandes projetos que se instalavam na região para a realização de obras com a possibilidade de progresso e crescimento econômico do país. 0 teor religioso e a menção de concretizar um sonho mostram que eram informações tendenciosas e, em parte, com caráter ufanista com relação às políticas estatais.

A construção da usina hidréletrica de Curuá-Una, segundo 0 JORNAL DE SANTARÉM (1973), despertava a realização de uma vontade da população, anciosa por um serviço de qualidade, que estivesse de acordo com o preço que cobrava, isso porque a Companhia Elétrica do Pará (CELPA), pelo menos em Santarém, "fornecia o que havia de pior em matéria de energia", pois as máquinas movidas por motores a diesel apagam e acendiam duas, três ou mais vezes ao dia, inclusive acreditava-se que antes da hidrelétrica funcionar a população iria ficar com $50 \%$ as escuras, ou totalmente.

Em 1971, o jornal de Santarém anunciou a chegada dos imigrantes da região sul. Segundo o jornal, os imigrantes dariam uma parcela de colaboração ao desenvolvimento regional, sendo que geralmente eram indivíduos ligados ao Batalhão de Engenharia e Construção (BEC). Como os imigrantes vinham para ajudar na integração da Amazônia ao restante do Brasil, era necessário serem bem recebidos, 0 ajudaria a construir a imagem do Brasil como uma pátria unida e forte.

No município de Santarém foram muito mais perceptíveis ações "de fora para dentro" que de "dentro para fora", ou seja, a interferência de empresas estatais e projetos de integração trouxeram pouco desenvolvimento efetivo para a população local, mas, de fato aumentavam a renda econômica nacional.

\footnotetext{
${ }^{1}$ Os jornais eram as principais fontes de informações do período estudado, nesse sentido, as perspectivas recebidas pela população santarena estavam sujeitas ao jogo de interesses dos políticos. Logo, essas considerações sobre os jornais feitas no decorrer do artigo teveram uma visão critica.
} 
A estrategia adotada pelo Estado nacional não se enquadra na perspectiva de desenvolvimento endógeno. De acordo com Barqueiro (2001) o desenvolvimento endógeno, deve se propor a atender as necessidades e demandas locais por meio de uma participação ativa da comunidade. Neste contexto, as pequenas e médias empresas devem ser as protagonistas no processo de desenvolvimento endógeno, devido a sua capacidade de flexibilização e organização empresarial.

Da maneira como se organizou e materializou as politicas de desenvolvimento e integração da Amazônia, nota-se o entendimento de desenvolvimento como crescimento econômico, e considera que este deve ser obtido através do uso das riquezas naturais. E este possibilitará o surgimento dos bônus do desenvolvimento cujo "objetivo comum é o de criar condições para o preenchimento do imenso vazio demográfico atravessado pelas rodovias e transforma-las, no futuro, em fator de penetração e de progresso" (JORNAL DE SANTARÉM , 1971).

O jornal do período descreve a situação:

Aqui em Santarém, entretanto, apesar de tudo quanto se tem recebido do Governo Revolucionário, quando o Grande Presidente M édici, de um modo eminentemente patriótico voltou as forças do seu Governo para a Amazônia, com a finalidade de desenvolvê-la para integrá-la de maneira decisiva ao contexto nacional, destacando se o nosso município como um dos importantes pontos de convergência de impulso de Governo. (JORNAL DE SANTARÉM, 1973).

0 ufanismo dos autores do jornal em relação ao presidente da república é explícito. Mesmo recohecendo o processo de censura, compreendemos que os jornalistas da época realmente acreditavam na ideia de desenvolvimento e nas polítcas do estado para região, a censura os proibia de levantar fatos contra o governo, mas não era obrigatória a prática ufanista.

Em outro momento o jornal defende-se além do desenvolvimento econômico, 0 desenvolvimento social:

0 progresso alcançou todos os recantos de nossa pátria e principalmente para nós os amazônidas ele veio de forma positiva e concreta, e não precisa ir a capital do Estado ou a outra parte para testemunhar o que afirmamos. Aqui mesmo em Santarém podemos observar os efeitos benfazejos do Movimento revolucionário. Eles estão representados no grande numero de escolas construídas, para o curso primário, no aumento das salas de aula para o nível médio, na criação do núcleo do centro de educação, na construção da hidroelétrica do Palhão, na rede de iluminação, na melhoria do abastecimento d'água. Enfim, podemos observar os resultados positivos da revolução democrática em tudo aquilo que por ela foi feito, inclusive até no direito que é assegurado aos seus adversários para abrirem a boca e dizerem tudo aquilo, Ihes vem a mente e que é concebido na ânsia de verem voltar os dias de baderna e da falta de respeito, em que os dinheiros públicos eram desviados para os empreendimentos particulares e o patrimônio do 
município era dilapidado em favor de meia dúzia. (JORNAL DE SANTARÉM, 1973)

Nesta citação nota-se a defesa dos governos militares e suas políticas desenvolvimentistas, além de presentar os ditadores como revolucionários e democráticos. 0 texto apresenta algumas obras e benefícios que o movimento revolucionário trouxe para Santarém e para o restante do Brasil. Percebemos o destaque para a construção da usina do Palhão entre as obras que contribuiu para o desenvolvimento da cidade. No entanto não percebemos os ônus desse processo de desenvolvimento, os impactos sociais e ambientais que este causou.

Thisse (2011) incita que "a estrutura centro-periferia é a consequência involuntária das decisões tomadas por um grande número de agentes econômicos em favor de seus próprios interesses". Ao analisar a região amazônica como área periférica temse, portanto, uma série de agentes econômicos, que podem ser empresas - as quais se instalaram na região com o provável objetivo de aumentar o índice demográfico e gerar emprego e renda para a região, a exemplo na produção de soja. Desta forma, percebe-se uma relação de dominação, que mesmo trazendo benefícios econômicos para a região, acarreta uma série de prejuízos ambientais e mesmo sociais.

Em outra perspectiva que ressalva um possível crescimento econômico, é importante frisar os impactos positivos ao considerar o pensar da população, o Jornal de Santarém de 5 de Maio de 1973:

\begin{abstract}
O PROGRESSO Está Chegando Pela Estrada
Já não são apenas os carros que vez ou outra chegam trazendo algumas cargas(...). Já estão chegando também os carros frigoridoos trazendo gêneros alimentícios que são vendidos diariamente (...). São as frutas, os legumes de boa qualidade que chegam para tornarem mais farta a mesa dos santarenos (...) cuja balança dos preços sempre esteve sujeita à lei da oferta e da procura. Esses e outros importantes aspectos positivos estão sendo apresentados pela grande rodovia da integração amazônica que num futuro bem próximo se transformará na grande arte'ria por onde correrá um fluxo constante, o progresso dessa vasta região.
\end{abstract}

A citação apresenta os aspectos positivos da política de desenvolvimento implantada na cidade, ainda em 1973, o jornal anunciava que a estrada de rodagem permitiu a inserção e integração da economia santarena com a de outras regiões do Brasil, e este é um fato que não pode ser negado, mesmo reconhecendo que a obra ainda hoje, 2015, não foi concluída. Atualmente, o transporte rodoviário de passageiros ocorre com relativa velocidade, em três ou quatro dias, é possivel sair de Santarém e chegar ao estado do Rio Grande do Sul. Portanto, compreendemos que em parte 0 ideal de integração foi alcançado, todavia, não esquecemos que o este projeto de integração custou caro, e tinha como objetivo a ocupação e manutenção da soberania territorial do Brasil. 
0 trecho da poesia intitulada "Transamazônica" retrata a respeito da rodovia:"De Recife à Humaitá, vendo à fronteira,Integras a Amazônia ao Sul e ao Centro,Formando uma só Pátria Brasileira,Para nela podermos viver dentro". (O JORNAL DE SANTARÉM , 17 de julho de 1971)

Pode-se perceber, deste modo, a grande relevância que possuia a rodovia no processo de agregação ao desenvolvimento, esta seria um importante meio para o escoamento de produtos, e somado ao transporte hidroviário integraria a Amazônia de maneira concreta ao restante do país. Souza (2014) comenta que

Durante a construção da rodovia e ao longo da existência da Transamazônica, Médici foi visto com bons olhos por aqueles que depositaram suas esperanças em sua presença e/ou no retorno de uma "era de ouro" em que a rodovia recebeu visitas de autoridades federais e também fortes investimentos no programa de colonização. (SOUZA, 2014. p.6).

Como possível forma integração, O JORNAL DE SANTARÉM (1971) destaca que os principais objetivos do Governo seriam executar a construção da Transamazônica e da Cuiabá Santarém, com a finalidade de conquistar e colonizar uma área superior à metade do território nacional, a considerar os aspectos fisiográficos, demográficos, econômicos e sociais do Nordeste e da Amazônia. De um lado, a Amazônia, rica em recursos naturais e demograficamente vazia. De outro, o Nordeste, constituídopor um sertão semiárido, que contava com uma população superior a 30 milhões de habitantes.

O Jornal do Baixo Amazonas ao abordar a contribuição do Porto das Docas do Pará, em Santarém, destaca o fato de que o porto estava inserido no plano de abertura de corredores de exportação do presidente M édici. E desde que foi inaugurado em 1974 ate 1978, movimentou mais de um milhão de toneladas de cargas variadas, superando as expectativas iniciais. (JORNAL DO BAIXO AMAZONAS, 1978).

De acordo com O JORNAL DE SANTARÉM (edição 19 de junho de 1971, s/p), “(...) 0 nôvo porto terá capacidade para receber navios de até 45 mil toneladdas e virá beneficiar os municípios de Almeirim, Alenquer, Aveiro, Juruti, M onte alegre, Óbidos, Prainha e Santarém". Segundo o autor, a ideia da construção de um porto no município de Santarém vinha a muito sendo cogitada, isso em razão da demanda constante existente no município, que na época já concentrava grande parte da produção do 0este do Pará.

A seguir, observam-se alguns depoimentos a respeito do progresso ocorrido no município de Santarém durante a década de 1970:

PROGRESSO PALPÁVEL

"Quase não reconheci Santarém, tão transformada pelo progresso que encontrei (...) tôda pessoa que chegava a São Paulo falava do progresso desta terra e eu ficava idealizando mentalmente êsse progresso. Hoje, ao chegar aqui, verifico que jamais poderia fazer uma idéia do desenvolvimento da 
terra, que está em ritmo acelerado. Belas praças, ruas asfaltadas (...)" (IDA DE JESUS PICANÇO, enfermeira paraense, depois de 23 anos de ausência de Santarém)

"Ano passado estive aqui. Posso afirmar que quem passa um ano fora de Santarém ao regressar encontra grandes modificações. Estou maravilhada com tanto progresso na minha terra. Visitei Curuá-una ano passado e êste ano, ao renovar a visita, observei o quanto se fez de trabalho para êxito dessa futura hidroelétrica. A emoção que sentimos é grande, ao vermos a grande atenção que o nosso brilhante presidente Garastazu Médici está dando a Santarém". (BERENICE CASTRO, O JORNAL DE SANTARÉM )

Através destes depoimentos, é possível perceber a forma que as notícias eram transferidas para população com teor de admiração, gratidão e solenidade a respeito dos projetos de integração, frisando que eles trariam desenvolvimento para sua região. Mudanças ocorridas na infraestrutura da cidade concretizaram-se, para os cidadãos, em ideais efetivos de desenvolvimento.

\section{CONSIDERAÇÕES FINAIS}

Através dos métodos utilizados na análise documental desta pesquisa, pode-se assumir que os planos de integração nacional foram, de acordo com a mídia, recebidos de forma esperançosa pela população. Mesmo no contexto do regime militar, aos quais muitos chamam de "Revolução democrática", acredita-se a partir dos textos jornalísticos que a população local possuía uma declarada esperança de que estes projetos trariam desenvolvimento econômico para a região - e em certa medida de fato o trouxeram.

Os projetos para viabilizar a integração, no entanto, mantiveram seu foco na exploração e extração de recursos naturais da Amazônia. 0 desenvolvimento a partir de uma perspectiva local foi colocado quase sempre em segundo plano. Isso porque economicamente a Amazônia era valorizada por ser uma vasta região cheia de riquezas que, de acordo com o pensamento da época, poderiam ser utilizadas para ajudar economicamente o país.

As formas de integração com os outras regiões ocorreram desconsiderando as especificidades da Amazônia. As consequências deste projeto de integração estão presentes também nos dias de hoje, pois alguns projetos em andamento na região desconhecem ou ignoram os efeitos que acarretam sobre as populações locais.

É importante a reflexão para as questões sociais e ambientais na Amazônia, que vêm sendo discutidas de forma mais intensa a partir da década 1990, com o surgimento do conceito de sustentabilidade, para que os recursos naturais sejam utilizados de maneira mais racional e consciente. Além disso, é preciso um olhar mais sensível para os anseios locais, suas reais necessidades e espectativas, para que assim a Amazônia possa se desenvolver de fato, e que seja valorizada pelo seu real potencial natural e social, não como um estoque de recursos naturais a serem explorados, ex- 
clusivamente para o crescimento econômico do país.

\section{REFERÊNCIAS}

ARM ENTANO, Isabella Maria Davenis. A integração e a não-integração da região amazônica ao território nacional. AUP 270 - Planejamento de Estruturas Urbanas e Regionais II. Universidade de São Paulo - Faculdade de Arquitetura e Urbanismo, 2010.

BARQUERO, Antonio Vázquez. Desenvolvimento endógeno em tempos de globalização. Tradução de Ricardo Brinco. Porto Alegre: Fundação de Economia e Estatística, 2001.

BECKER, Bertha. Por que a participação tardia da Amazônia na formação econômica do Brasil? In: $\mathbf{5 0}$ anos de Formação Econômica do Brasil: Ensaios sobre a obra clássica de Celso Furtado. Rio de Janeiro: IPEA, 2009.

BREDA, Francisco de Assis; ANDRADE, Priscilla. A administração e as teorias do desenvolvimento. Facef - Revista Eletrônica de Administração, v. 01, p. 01 a 31, jun/dez 2002.

BOCCHI, João Ildebrando; GARGIULO, Felipe Freitas. Desenvolvimentismo e a CEPAL: da industrialização por substituição de importações à transformação produtiva com equidade.. In: 20 ENCONTRO DE INICIAÇÃO CIENTÍFICA DA PUC/SP. Desafios Contemporâneos na Prática Científica. Anais... São Paulo: PUC, 2011.

BUARQUE, Sérgio. Metodologia de planejamento do desenvolvimento local e sustentável. Cap I - Desenvolvimento Local. Projeto de Cooperação Técnica INCRA/IICA. Brasília, p. 1-7, 1999.

CRUZ, Bruno de Oliveira; FURTADO, Bernardo Alves; M ONASTERIO, Leonardo; JÚNOR, Waldery Rodrigues (organizadores). Economia regional e urbana: teorias e métodos com ênfase no Brasil. Brasília: Ipea, 2011.

FURTADO, Celso. 0 mito do desenvolvimento econômico. Rio de Janeiro: paz e terra. 1974.

HABERM AS, Jürgen. Técnica e ciência como ideologia. Lisboa: Edições 70, 1968.

LIMA, Ana Carolina da Cruz; SIM ÕES, Rodrigo Ferreira. Teorias do desenvolvimento regional e suas implicações de política econômica no pós-guerra: o caso do Brasil. In: Desenvolvimento Desigual e Transmissão Inter-regional do Crescimento sob a ótica de Albert 0. Hirschman. Texto para discussão $\mathrm{N}^{\circ}$ 358. Belo Horizonte: UFM G/Cedeplar, p. 16-21, 2009.

Jornal do Baixo Amazonas. ANO I. Santarém (PA). 1978.

0 jornal de Santarém: Semanario noticioso, defensor dos interesses santarenenses. Ano XXXI. Santarém, 1971.

0 jornal de Santarém: Semanario noticioso, defensor dos interesses santarenenses. Ano XXXIII. Santarém, 1973.

M ARTINOLI, Simone. 0 Estado Brasileiro e o processo de produção do espaço no 
Acre. 2004. 257 f. Tese (Doutorado em Urbanismo) - Faculdade de Arquitetura e Urbanismo da Universidade de São Paulo, São Paulo, 2004.

NASCIM ENTO, Elimar Pinheiro. Trajetória da sustentabilidade: do ambiental ao social, do social ao econômico. Estudos avançados, São Paulo 26 (74). p. 51- 64.2012

SANTOS, Lara; SANTOS, Tatiana. As contribuições do modelo econômico de Albert Hirschman para a administração do desenvolvimento. Cadernos de aulas LEA. Bahia. $\mathrm{N}^{\circ} 1$, Vol. 1. p. 1-19, nov. 2012.

SCOTTO, Gabriela; CARVALHO, Isabel Cristina de Moura; GUIM ARÃES, Leandro Belinaso. Desenvolvimento sustentável. 6a edição. Petrópolis: Editora Vozes, 2011.

Artigo recebido em 28 de maio de 2015.

Aprovado em 17 de novembro de 2016. 